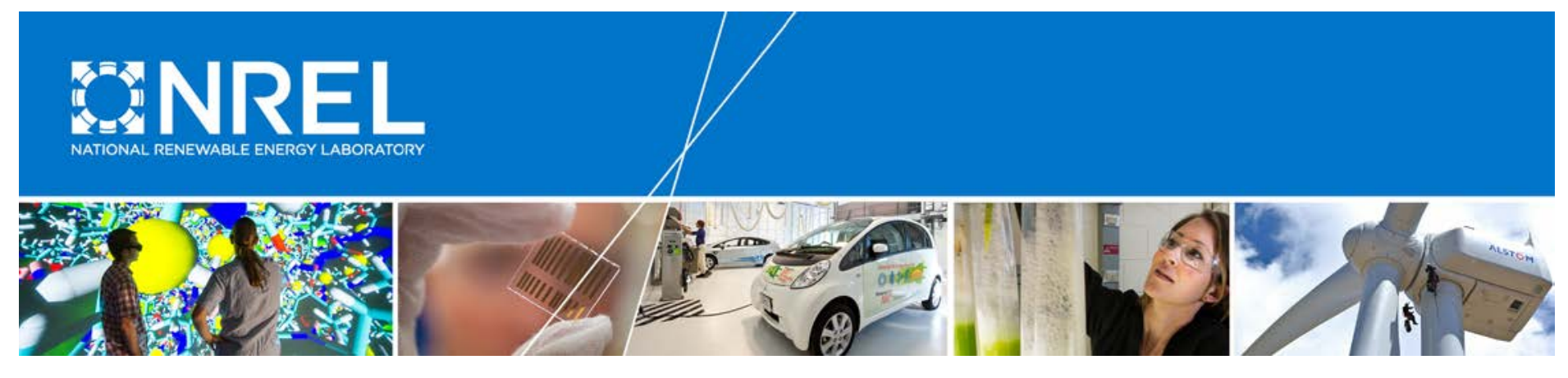

\title{
Fast Charge Battery Electric Transit Bus In-Use Fleet Evaluation
}

\section{Preprint}

\section{Robert Prohaska, Leslie Eudy, and Kenneth Kelly}

To be presented at ITEC 2016: IEEE Transportation Electrification Conference and Expo

Dearborn, Michigan

June $27-29,2016$

(c) 2016 IEEE. Personal use of this material is permitted. Permission from IEEE must be obtained for all other uses, in any current or future media, including reprinting/republishing this material for advertising or promotional purposes, creating new collective works, for resale or redistribution to servers or lists, or reuse of any copyrighted component of this work in other works.

NREL is a national laboratory of the U.S. Department of Energy Office of Energy Efficiency \& Renewable Energy Operated by the Alliance for Sustainable Energy, LLC

This report is available at no cost from the National Renewable Energy Laboratory (NREL) at www.nrel.gov/publications.

\section{Conference Paper}

NREL/CP-5400-66098

May 2016 


\section{NOTICE}

The submitted manuscript has been offered by an employee of the Alliance for Sustainable Energy, LLC (Alliance), a contractor of the US Government under Contract No. DE-AC36-08GO28308. Accordingly, the US Government and Alliance retain a nonexclusive royalty-free license to publish or reproduce the published form of this contribution, or allow others to do so, for US Government purposes.

This report was prepared as an account of work sponsored by an agency of the United States government. Neither the United States government nor any agency thereof, nor any of their employees, makes any warranty, express or implied, or assumes any legal liability or responsibility for the accuracy, completeness, or usefulness of any information, apparatus, product, or process disclosed, or represents that its use would not infringe privately owned rights. Reference herein to any specific commercial product, process, or service by trade name, trademark, manufacturer, or otherwise does not necessarily constitute or imply its endorsement, recommendation, or favoring by the United States government or any agency thereof. The views and opinions of authors expressed herein do not necessarily state or reflect those of the United States government or any agency thereof.

This report is available at no cost from the National Renewable Energy Laboratory (NREL) at www.nrel.gov/publications.

Available electronically at SciTech Connect http:/www.osti.gov/scitech

Available for a processing fee to U.S. Department of Energy and its contractors, in paper, from:

U.S. Department of Energy

Office of Scientific and Technical Information

P.O. Box 62

Oak Ridge, TN 37831-0062

OSTI http://www.osti.gov

Phone: 865.576.8401

Fax: 865.576.5728

Email: reports@osti.gov

Available for sale to the public, in paper, from:

U.S. Department of Commerce

National Technical Information Service

5301 Shawnee Road

Alexandria, VA 22312

NTIS http://www.ntis.gov

Phone: 800.553 .6847 or 703.605 .6000

Fax: 703.605.6900

Email: orders@ntis.gov 


\title{
Fast Charge Battery Electric Transit Bus In-Use Fleet Evaluation
}

\author{
Robert Prohaska, Kenneth Kelly, Leslie Eudy \\ National Renewable Energy Laboratory \\ Robert.Prohaska@nrel.gov, Kenneth.Kelly@nrel.gov, Leslie.Eudy@nrel.gov
}

\begin{abstract}
The focus of this interim fleet evaluation is to characterize and evaluate the operating behavior of Foothill Transit's fast charge battery electric buses (BEBs). Future research will compare the BEBs' performance to conventional vehicles. In an effort to better understand the impacts of drive cycle characteristics on advanced vehicle technologies, researchers at the National Renewable Energy Laboratory analyzed over 148,000 $\mathbf{k m}$ of in-use operational data, including driving and charging events. This analysis provides an unbiased evaluation of advanced vehicle technologies in real-world operation demonstrating the importance of understanding the effects of road grade and heating, ventilating and air conditioning requirements when deploying electric vehicles. The results of this analysis show that the Proterra BE35 demonstrated an operating energy efficiency of 1.34 $\mathrm{kWh} / \mathrm{km}$ over the data reporting period.
\end{abstract}

\section{INTRODUCTION}

In March 2014, Foothill Transit began operating a fleet of battery electric buses (BEBs) in its service area in the San Gabriel and Pomona Valley region of Los Angeles County, California. These electric buses, produced by Proterra, Inc., are 35-foot long, composite body buses that are capable of being charged on-route via Eaton 500-kW fast chargers (Fig. 1). Foothill Transit is collaborating with the California Air Resources Board and the U.S. Department of Energy's (DOE's) National Renewable Energy Laboratory (NREL) in Golden, Colorado, to evaluate the buses in revenue service [1]. NREL has extensive experience conducting fleet evaluations and has been evaluating advanced technology buses for several years under funding from the DOE's Vehicle Technology Office and the U.S. Department of Transportation's Federal Transit Administration.

This research report was sponsored by the Vehicle Systems Program's Advanced Vehicle Testing Activity within the DOE's Vehicle Technologies Office.

The objectives of these evaluations are to provide comprehensive, unbiased evaluations of advanced technology bus development and performance compared to conventional baseline vehicles. These evaluations help manufacturers improve their design requirements, test procedures, and ultimately their commercial success, while at the same time informing fleet managers to allow them to better select appropriate energy-efficient, low-emission vehicle technologies that fit their operational goals and requirements.

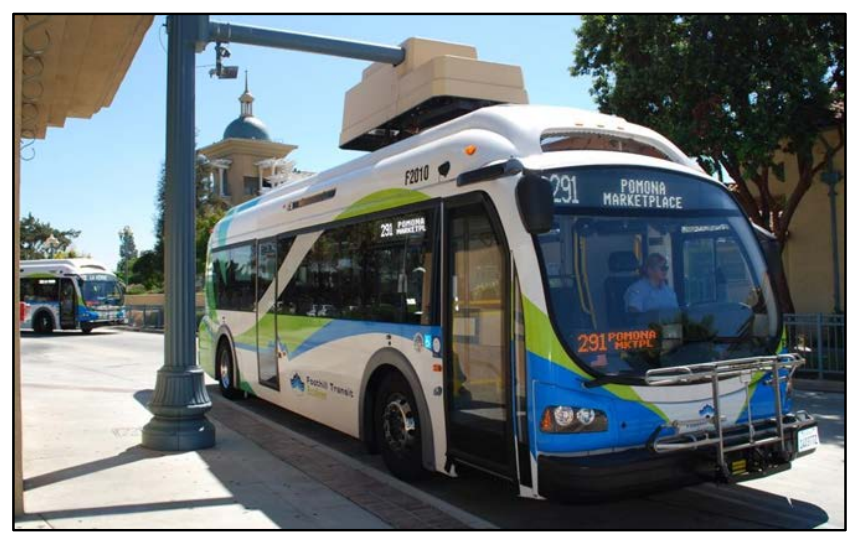

Fig. 1. Proterra BE35 Fast Charge Battery Electric Transit Bus (NREL/Leslie Eudy)

In 2013 Foothill Transit purchased 12 BEBs through a $\$ 10.2$ million grant under the Federal Transit Administration's Transit Investments for Greenhouse Gas and Energy Reduction (TIGGER) Program. Foothill Transit's project goal was to fully electrify one route in its service area-Line 291, which is an approximately $26.8-\mathrm{km}$ route between La Verne and Pomona as shown in Fig. 2-and to investigate the feasibility of BEB technology for other routes. The details of the Proterra BE35 are shown in Table I.

TABLE I.

ProterRa BE35 BATTERY EleCtric Bus SPECIFICATIONS

\begin{tabular}{|l|c|}
\hline Bus manufacturer & Proterra \\
\hline Bus model & BE35 \\
\hline Model year & 2014 \\
\hline Total length & $10.67 \mathrm{~m}(35 \mathrm{ft})$ \\
\hline Total height & $3.28 \mathrm{~m}(10.75 \mathrm{ft})$ \\
\hline Wheelbase & $6.02 \mathrm{~m}(237 \mathrm{in})$. \\
\hline Curb weight & $12,555 \mathrm{~kg}(27,680 \mathrm{lb})$ \\
\hline Gross vehicle weight rating & $16,928 \mathrm{~kg}(37,320 \mathrm{lb})$ \\
\hline Passenger capacity & 35 seated / 18 standing \\
\hline Battery manufacturer / model & Altairnano / TerraVolt 368 \\
\hline Battery type & $368-\mathrm{V}$ lithium titanate \\
\hline Battery energy/capacity & $88 \mathrm{kWh} / 60 \mathrm{Ah}$ \\
\hline Number of packs & $8(6 \mathrm{floor}, 2 \mathrm{roof})$ \\
\hline Motor manufacturer / model & UQM / PP220 \\
\hline Motor power nominal & $120 \mathrm{~kW}(161 \mathrm{hp})$ \\
\hline Motor power peak & $220 \mathrm{~kW}(295 \mathrm{hp})$ \\
\hline Fast charging peak power & $500 \mathrm{~kW}$ \\
\hline Transmission gear ratios & $3.53: 1 \mathrm{and} 1: 1$ \\
\hline Cabin air conditioning & Thermoking REH-M6 \\
\hline Cabin heater & $11-\mathrm{kW}$ electric resistance \\
\hline
\end{tabular}




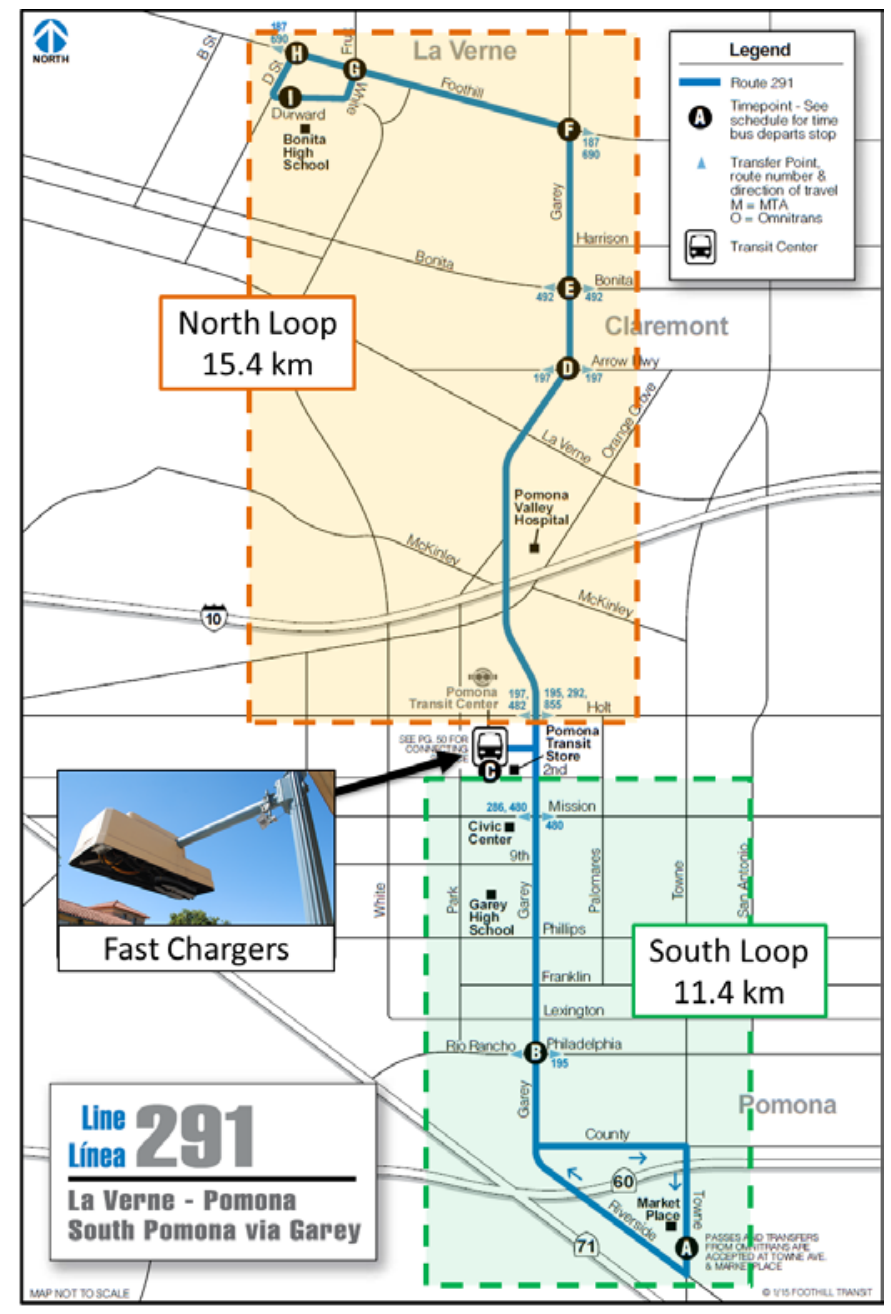

Fig. 2. Route map for Line 291 shown in blue. Two fast chargers are located at the Pomona Transit Center. (Route map courtesy of Foothill Transit).

\section{DATA ANALYSIS}

In early 2015, Proterra provided researchers at NREL with 148,605 kilometers of $2-\mathrm{Hz}$ in-use operation data from 12 electric transit buses operating in Foothill Transit's fleet. These data were from four separate time periods to balance out potential effects of seasonality and changes in ridership as seen in Fig. 3.

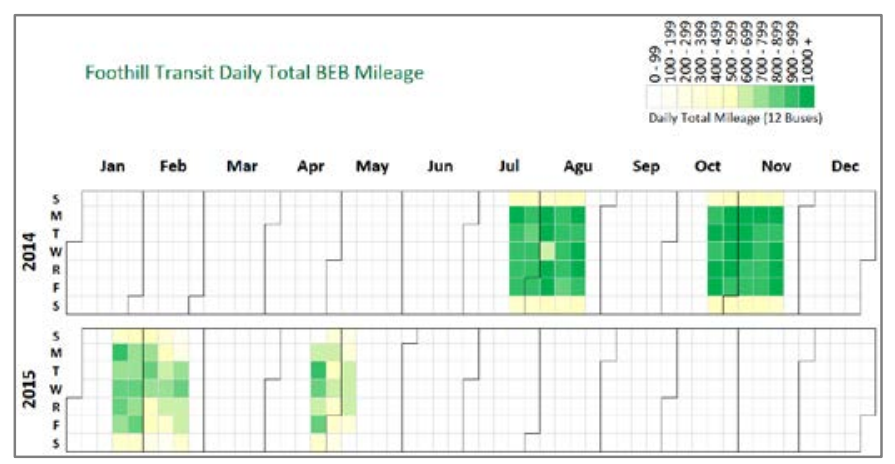

Fig. 3. Data collection periods shaded according to daily mileage accumulation for all 12 BEBs
Successful deployment of advanced vehicle technologies is highly dependent on correctly matching the technology with an appropriate duty cycle. There are many ways to characterize a vehicle's duty cycle, but by focusing first on the kinematics of daily operation, we can better understand how vehicles are operating and begin to understand the drive cycle requirements of this duty cycle. In this paper, duty cycle refers to the operational cycle of the vehicle, which includes how, when, and where the vehicle is dispatched; how many riders are picked up; how often the vehicle is recharged; etc. The term drive cycle describes the kinematics, or motion, of the vehicle. Each drive cycle will include a number of metrics characterizing the vehicle's behavior, such as maximum speed, average speed, distance traveled, frequency of stops, acceleration rates, idle time, etc.

Fig. 4 shows a typical drive cycle speed trace for a BEB in operation on Line 291. Three separate charge events with an average duration of 5 to 6 minutes are included in this figure and are marked accordingly, along with the relative location (North or South Loop). The smaller North and South Loops make up the full route for Line 291. The purple line shows the vehicle speed trace of the bus while the blue line shows the battery pack state of charge (SOC); both of these metrics use the left vertical axis. The red line, with the vertical axis on the right, shows cumulative distance. When examining the change in slope of the battery SOC curve on the portion of the figure labeled "North Loop," we can see varying degrees of discharge rates. These variances are attributed to the slight amount of road grade on Line 291 as the north end of the loop is approximately $92 \mathrm{~m}$ above the Pomona Transit Center. The first portion of the North Loop, starting at approximately $4: 18$ p.m. with a battery pack SOC of $80 \%$ shows a faster discharge rate (steeper slope of the blue line) due to the bus gaining elevation. The second half of the North Loop has a slower discharge rate (shallower slope of blue line) as the bus returns to the Pomona Transit Center with a battery pack SOC of approximately $32 \%$. While $92 \mathrm{~m}$ is not a significant amount of elevation change over 7.7 $\mathrm{km}$ (approximately half of the North Loop), there is a noticeable effect on the power required for operating the BEB and demonstrates the importance of road grade when considering energy storage requirements.

Table II lists several duty cycle and drive cycle metrics describing the operation and driving behavior seen in Foothill Transit's BEBs. With a total of 774 days of operation analyzed, the buses averaged 13.9 hours of operational time per day, 6.7 of which the vehicles are in motion with an average of 444 stops per day. The average driving speed was $28.42 \mathrm{~km} / \mathrm{h}$ with an average daily maximum speed of $72.09 \mathrm{~km} / \mathrm{h}$. 


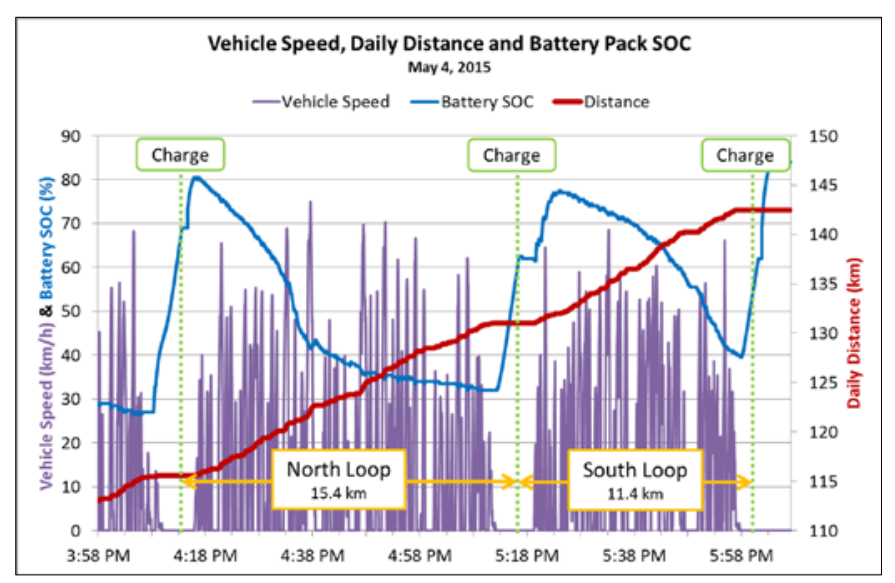

Fig. 4. Vehicle speed, battery pack SOC, and distance for one typical "loop" on Line 291 with three charge events shown

TABLE II.

OPERATING METRICS

\begin{tabular}{|l|c|}
\hline \multicolumn{1}{|c|}{ Metric } & Total \\
\hline Total number of operating days & 774 \\
\hline Total number of vehicles & 12 \\
\hline Total distance analyzed $(\mathrm{km})$ & 148,605 \\
\hline
\end{tabular}

\begin{tabular}{|l|c|}
\hline \multicolumn{1}{|c|}{ Metric } & Daily Average \\
\hline Average kinetic intensity $(1 / \mathrm{km})$ & 1.71 \\
\hline Average driving speed $(\mathrm{km} / \mathrm{h})$ & 28.42 \\
\hline Average maximum speed $(\mathrm{km} / \mathrm{h})$ & 72.09 \\
\hline Average daily distance $(\mathrm{km})$ & 192.00 \\
\hline Average operating time (hours) & 13.9 \\
\hline Average driving time (hours) & 6.7 \\
\hline Average number of stops per day & 444.29 \\
\hline Average number of stops per kilometer & 2.31 \\
\hline Average acceleration $\left(\mathrm{m} / \mathrm{s}^{2}\right)$ & 0.44 \\
\hline Average deceleration $\left(\mathrm{m} / \mathrm{s}^{2}\right)$ & 0.55 \\
\hline
\end{tabular}

One metric often used to describe the drive cycle of a particular vehicle is kinetic intensity [2]. Kinetic intensity is a relative measure of driving aggressiveness and is based on the relationship between the energy used for accelerating a vehicle versus the amount of energy used to overcome aerodynamic drag. Comparing daily average kinetic intensity to average driving speed (Fig. 5), we can see that there is very little variation in the data set as $99.7 \%$ of all the values fall within the orange rectangle representing values within \pm 3 standard deviations from the mean.

From further investigation of the driving patterns and behaviors of these BEBs, we can see in Fig. 6 the strong linear relationship between the daily number of stops and daily distance travelled with an $\mathrm{R}^{2}$ value of 0.9571 , indicating that $95.7 \%$ of the variation between daily distance and stops per day is explained by the linear regression model. Looking at the frequency of stops on a distance basis as a function of acceleration, we can see in Fig. 7 that the buses average 2.31 stops per kilometer and have a slightly higher average rate of deceleration than acceleration.

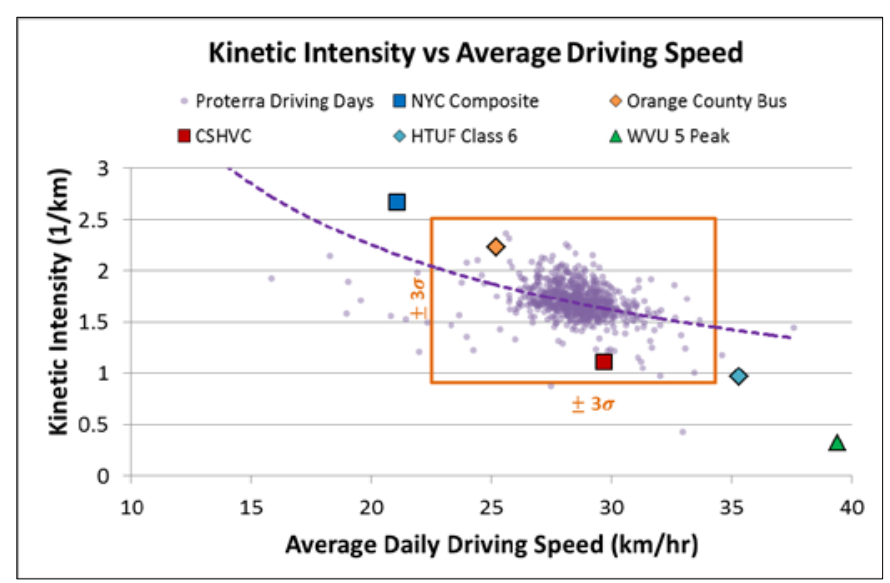

Fig. 5. Kinetic intensity vs. average driving speed for all Proterra BEBs with $\pm 3 \sigma$ reference box. Standard test cycles are also shown.

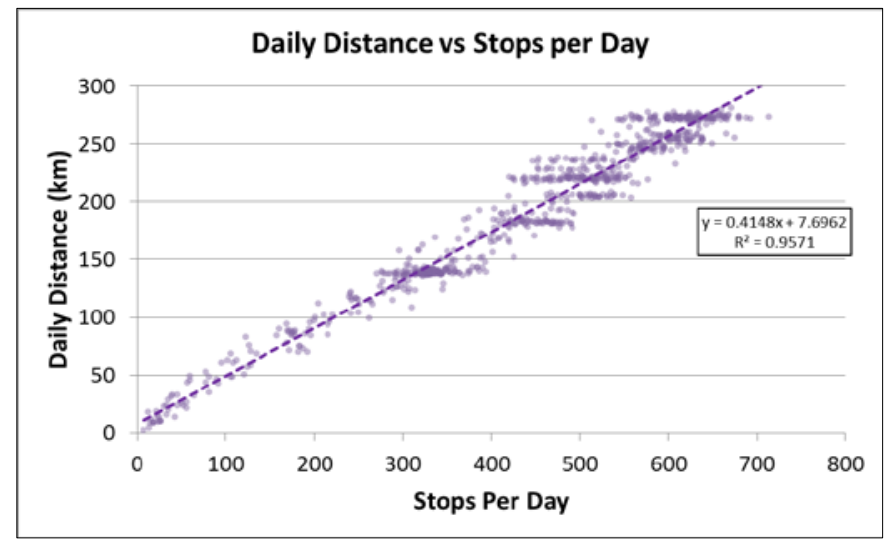

Fig. 6. Daily distance travelled vs. number of stops per day for all vehicles

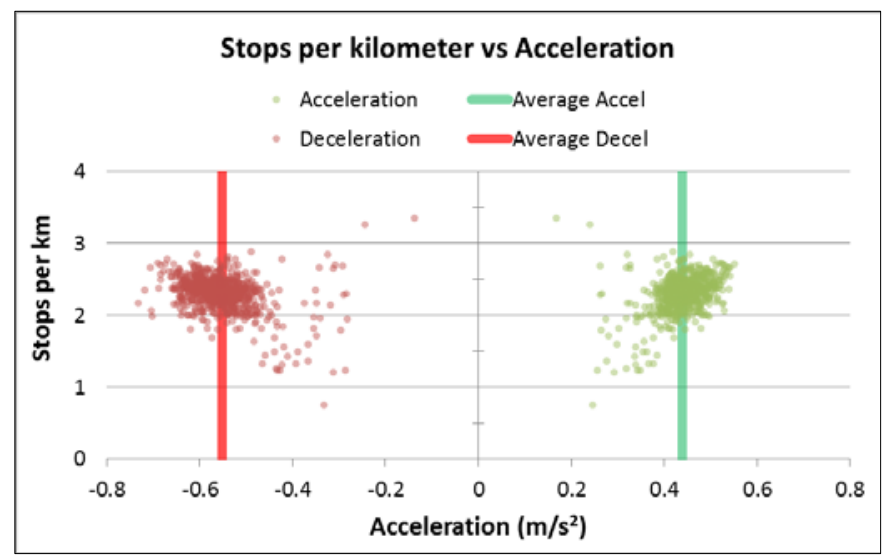

Fig. 7. Average daily acceleration rates vs. stops per kilometer

Fig. 8 shows the strong relationship between daily operating time and daily driving time with an $\mathrm{R}^{2}$ value of 0.9655 for the linear fit trend line, which shows that on average the vehicles are only in motion about $48 \%$ of the time they are in operation. These strong linear relationships in both Fig. 6 and Fig. 8 are indicative of the repetitive nature of this duty cycle as the buses travel the same stretch of road and have the same designated passenger pick-up stops. 


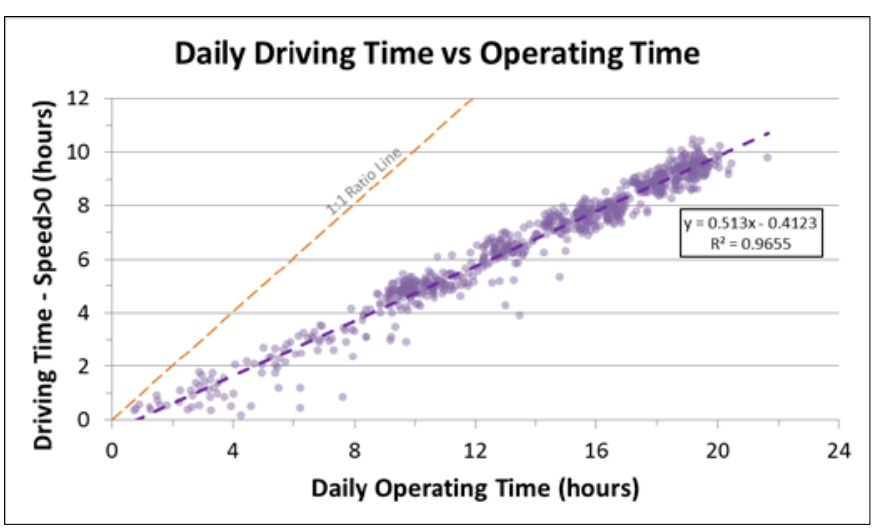

Fig. 8. Distribution of driving time where speed is greater than zero vs. amount of time when system is "ON" for all vehicles.

Fig. 9 shows the calculated battery power versus vehicle speed distribution for all vehicles. This figure demonstrates the tractive and regenerative power of the BEBs where positive power represents regenerative braking and charging (charging only at speed equal to zero) and the negative power indicates power leaving the battery pack for tractive energy or auxiliary loads. The vertical line at approximately $20 \mathrm{~km} / \mathrm{h}$ is a function of the two-speed transmission downshifting control strategy.

The BEBs deployed on this electrified route demonstrated an overall average efficiency of $1.34 \mathrm{kWh} / \mathrm{km}$. On an equivalent energy basis, this equates to 7.43 kilometers per diesel liter equivalent. This average efficiency was calculated using data provided by Proterra from July 2014 through June 2015 using the charging energy delivered to the battery packs of the BEBs and the total distance travelled. The overall fleet average efficiency includes the energy required to operate all accessory loads such as the heating, ventilating, and air conditioning (HVAC) system and fluctuates in response to average temperature, as seen in Fig. 10.

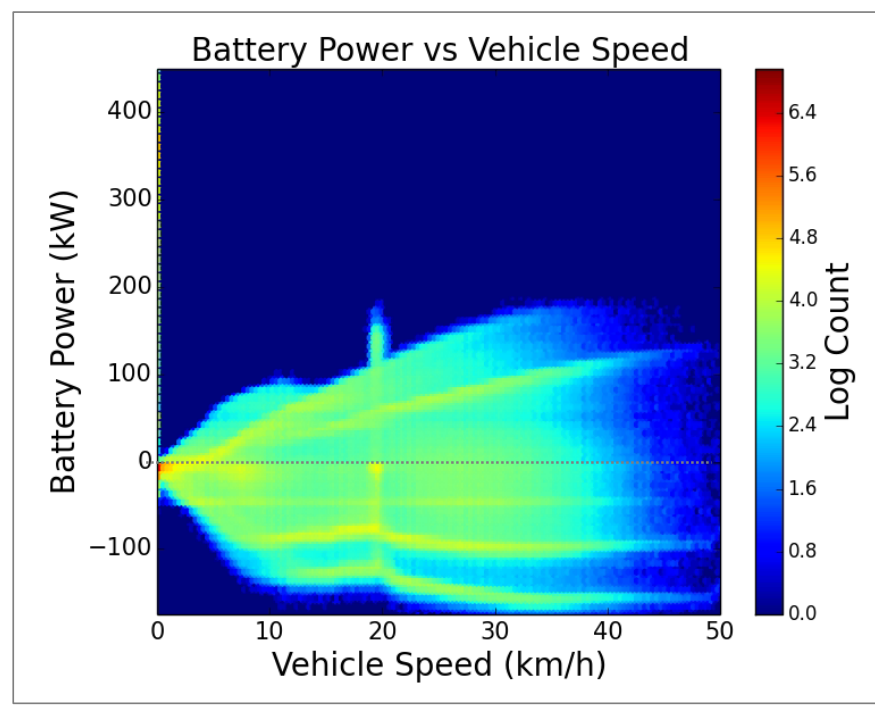

Fig. 9. Vehicle speed vs. battery pack power for all vehicles over the entire reporting period. Positive power indicates energy into the battery pack, and negative power indicates energy use.

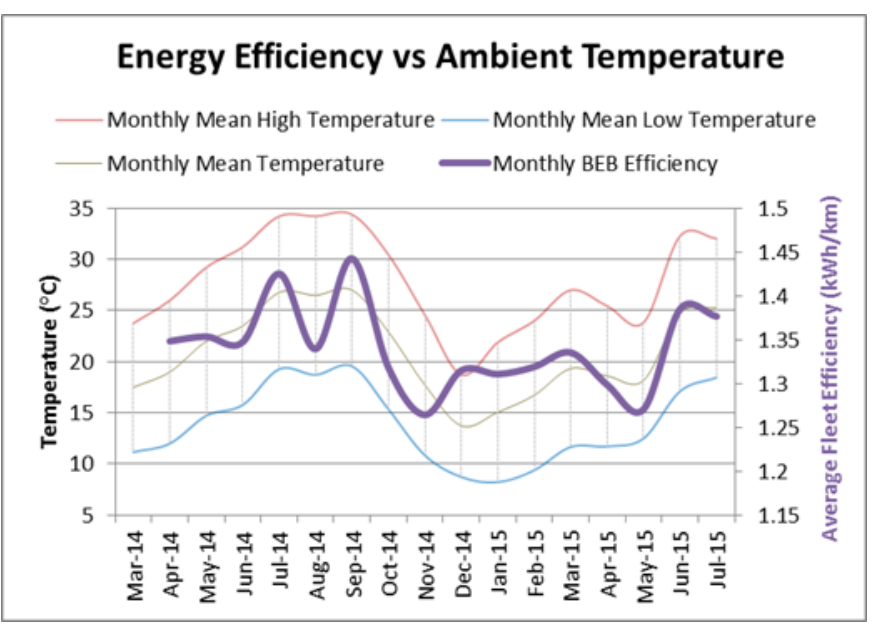

Fig. 10. BEB energy efficiency vs. mean, mean maximum, and mean minimum temperatures

The average monthly temperatures are from National Oceanic and Atmospheric Administration [3] measurements taken at the Ontario, California, airport, which is approximately $15 \mathrm{~km}$ from the Pomona Transit Center, where the BEBs are charged. The monthly BEB fleet efficiency fluctuates relative to average temperature with efficiency dropping when temperatures are higher and the buses require use of air conditioning as well as when temperatures drop, requiring the use of the electric heater. The months of highest efficiency have average high temperatures less than $25^{\circ} \mathrm{C}$ and average low temperatures greater than $11^{\circ} \mathrm{C}$, requiring the least amount of energy for passenger comfort.

Looking at the charging power in more detail, we can see in Fig. 11 that the majority of charging power is delivered to the lithium titanate battery pack at approximately $360 \mathrm{~kW}$ with maximum charging power of $450 \mathrm{~kW}$ and an average charging power of $319.3 \mathrm{~kW}$ as measured at the battery pack. The small peak near $50 \mathrm{~kW}$ represents the use of lower-power chargers installed at the maintenance garage. The bimodal peaks at the higher charging power levels are a result of charging control strategies employed by Proterra to manage peak loads at the Pomona Transit Center when two buses are charged simultaneously. Table III lists charging and energy use-related metrics describing the operation and efficiency seen in Foothill Transit's BEBs. 


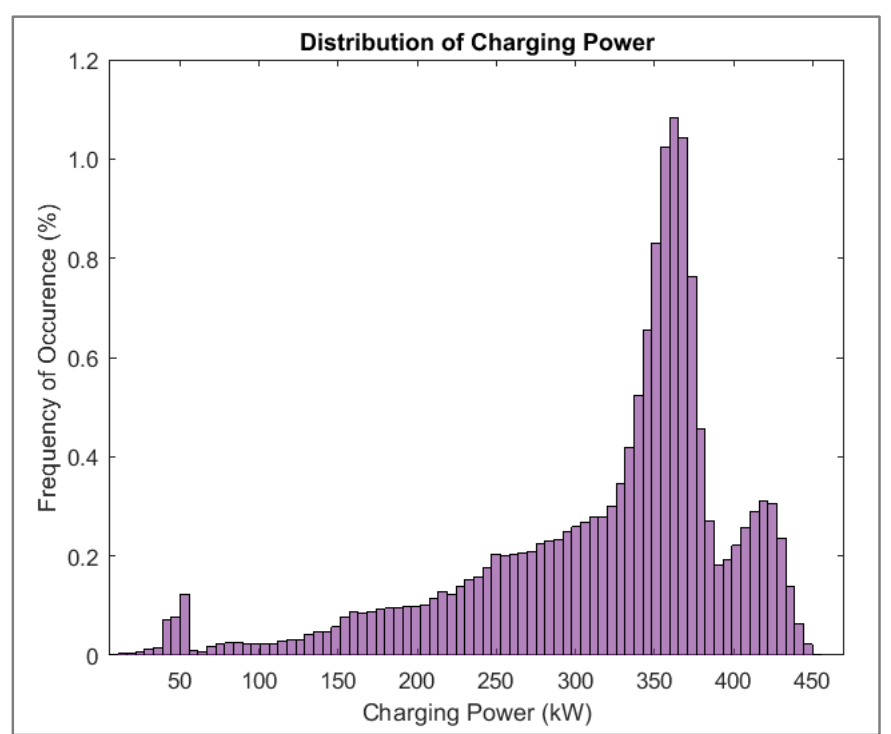

Fig. 11. Distribution of charging power at the battery pack

The BEBs are charged on route at the Pomona Transit Center an average of 12.5 times per day via one of two overhead conductive chargers, shown in Fig. 12, transferring on average $19.48 \mathrm{kWh}$ (standard deviation $0.89 \mathrm{kWh}$ ) of energy per charge with an average charge duration of just 4.99 minutes. The average charging energy delivered equates to only $22 \%$ of the $88 \mathrm{kWh}$ of total energy storage, indicating possible opportunities for battery pack downsizing, less frequent charging, or longer routes.

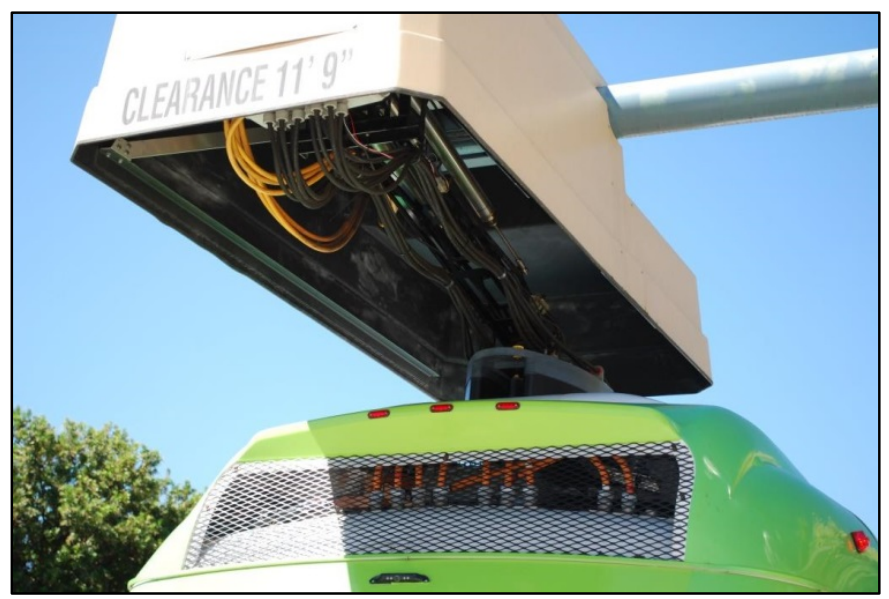

Fig. 12. A Foothill BEB docked with the 500-kW fast charger at the Pomona Transit Center (NREL/Leslie Eudy)

TABLE III

Cumulative CHARging AND OPERATING EFFICIENCY METRICS (JULY 2014 - JUNE 2015)

\begin{tabular}{|l|c|}
\hline \multicolumn{1}{|c|}{ Metric } & Total \\
\hline Average charge events per day & 12.5 \\
\hline Average energy per charge & $19.48 \mathrm{kWh} \mid \sigma: 0.89$ \\
\hline Average charge length & $4.99 \mathrm{Minutes} \mid \sigma: 0.21$ \\
\hline Average operating efficiency & $\begin{array}{c}1.34 \mathrm{kWh} / \mathrm{km} \mid \sigma: 0.053 \\
(2.15 \mathrm{kWh} / \mathrm{mi} \mid \sigma: 0.086)\end{array}$ \\
\hline
\end{tabular}

The docking process requires very little driver interaction as it is a semi-automated process. Each vehicle is equipped with a unique radio-frequency identification tag that the charging heads use to initialize the docking procedure. The vehicle is stopped by the driver in front of the charging head, the charging head recognizes the vehicle, and the vehicle is put into a semiautonomous creep mode and driven forward as the charging head lowers from the overhead dock to align with the vehicle's roof-mounted guide. Once the vehicle is in place, it is automatically stopped, and the driver places it in park before charging commences.

Fig. 13 shows a typical day of operation for a single BEB on Line 291. The bus travels a total of $250 \mathrm{~km}$ and is charged a total of 18 times with the battery SOC never dropping below $45 \%$. Fig. 14 shows that this charging behavior is consistent with the larger fleet operation where the average battery pack SOC is equal to $75.4 \%$ and the battery pack rarely drops below $50 \%$ SOC.

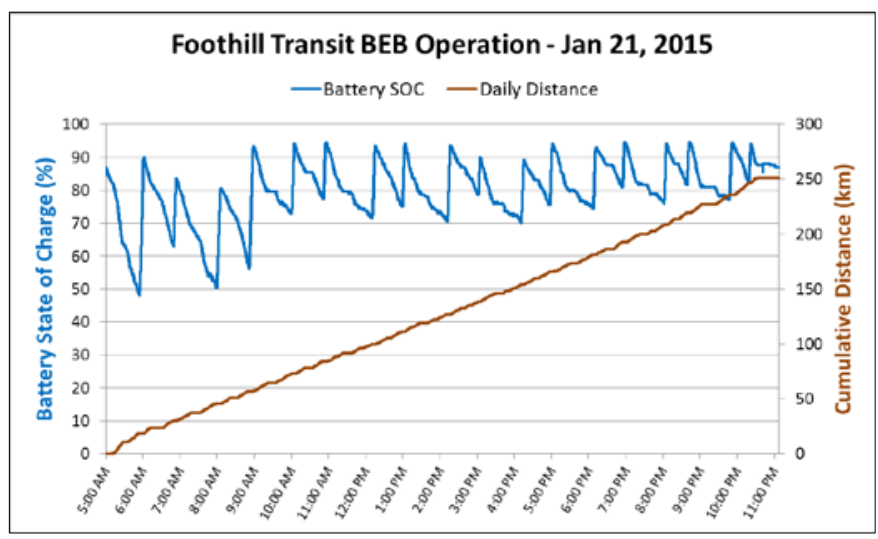

Fig. 13. Typical day of operation showing average battery pack SOC and cumulative distance travelled

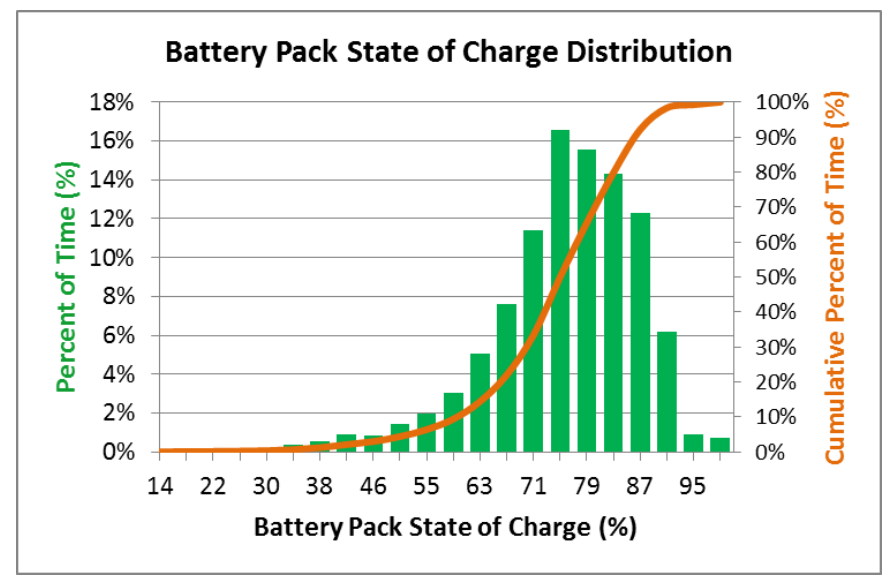

Fig. 14. Vehicle-reported SOC for all BEBs over the entire data reporting period

This battery pack SOC distribution curve also indicates the potential opportunities to optimize deployment of the BEBs on Line 291 as the buses spend less than $6 \%$ of their time at an SOC less than $55 \%$. Operationally, the buses could be charged 
less frequently on route, which would allow drivers to get back on schedule if they are delayed. Systematically, there is a potential opportunity to reduce the size of the energy storage system on the vehicles running this particular route to reduce weight and purchase price.

\section{CONCLUSION}

This paper emphasizes the importance of understanding how a vehicle's drive cycle and operating environment influence its overall duty cycle and how that duty cycle impacts the overall performance of advanced vehicle technologies. While the BEBs demonstrated an energy efficiency of $1.34 \mathrm{kWh} / \mathrm{km}$, road grade and non-tractive energy demands such as HVAC can have a significant effect on overall energy efficiency and must be taken into account when determining the feasibility of deploying advanced technologies. While the data showed seasonal variation in energy efficiency, additional analysis is required to accurately define the thermal load characteristics of these BEBs to isolate the HVAC system power requirements specific to this operational duty cycle.

\section{FUTURE RESEARCH}

Future research will done to compare the dedicated BEB Line 291 to a broader set of Foothill Transit routes using in-use data collected from conventional compressed natural gas buses randomly dispatched throughout the Foothill Transit service area. Through modeling and simulation, researchers will be able to identify other routes that would be well suited for electrification. In addition to benchmarking the operational efficiency of BEBs against compressed natural gas buses using in-field data, researchers plan to perform controlled chassis dynamometer testing to characterize efficiency over a range of drive cycles. Researchers also plan to investigate the impacts of HVAC requirements on energy efficiency and identify areas for potential improvement.

\section{ACKNOWLEDGMENT}

This work was sponsored by the Vehicle Systems Program's Advanced Vehicle Testing Activity within the DOE's Vehicle Technologies Office under Contract No. DE-AC36-08GO28308 with the National Renewable Energy Laboratory. This evaluation at Foothill Transit would not have been possible without the support and cooperation of many people. The authors thank the following individuals:

DOE: David Anderson and Lee Slezak. California Air Resources Board: Yachun Chow, Jennifer Lee, Craig Duehring. Foothill Transit: Roland Cordero, T.J. Nass, and Andrew Papson. Proterra: Mike Finnern and Joel Torr.

The U.S. Government retains and the publisher, by accepting the article for publication, acknowledges that the U.S. Government retains a nonexclusive, paid-up, irrevocable, worldwide license to publish or reproduce the published form of this work, or allow others to do so, for U.S. Government purposes.

\section{REFERENCES}

[1] L. Eudy, R. Prohaska, K. Kelly, and M. Post, "Foothill Transit battery electric bus demonstration results," NREL/TP-5400-65274. Golden, CO: National Renewable Energy Laboratory, November 2015.

[2] M. O'Keefe, A. Simpson, K. Kelly, and D. Pedersen, "Duty cycle characterization and evaluation towards heavy hybrid vehicle applications," SAE Technical Paper 2007-01-0302, 2007. doi:10.4271/2007-01-0302.

[3] Monthly Summaries of the Global Historical Climatology Network Daily (GHCN-D). GHCND:USW00003102. NOAA National Climatic Data Center. Accessed 8/6/2015.

http://www.ncdc.noaa.gov/ghenm/v3.php. 